\title{
ANÁLISES DAS MANIFESTAÇÖES PATOLOGICA: ESTUDO DE CASO EM UMA ESCOLA NA CIDADE DE JUAZEIRO DO NORTE - CEARÁ
}

\author{
Morais, JoÃo Marcos Pereira de \\ Profissão: Tecnólogo \\ Instituição: URCA \\ Ceará, Brasil \\ e-mail: joaomarcostecnologo@gmail.com \\ Lôbo, Josefa Missiliene CoRdeiro \\ Profissão: Tecnóloga \\ Instituição: URCA \\ Ceará, Brasil \\ e-mail: lobomissilene@gmail.com
}

\author{
CIRINO, MIGUEL ADRIANO GONÇALVES \\ Profissão: Professor e Estudante \\ Instituição: URCA \\ Ceará, Brasil \\ e-mail: miguel.goncalves@urca.br
}

\author{
OLIVEIRA, BRUNO BARBOSA DE \\ Profissão:Professor \\ Instituição: URCA \\ Ceará; Brasil \\ e-mail:bruno.barbosa@urca.br
}

\section{RESUMO}

Para o desenvolvimento das habilidades cognitivas dos alunos é necessário, ao menos, que os ambientes da edificação não dificultem o processo de ensino-aprendizagem, como na ocorrência de lugares insalubres e que apresentem patologias. A escola escolhida possui público formado por alunos do ensino fundamental, e em sua maioria de baixa renda. Assim, implica-se na necessidade de avaliação periódica do estado de conservação do edifico, uma vez que a última reforma e ampliação ocorreu no ano de 2011, desde então não é feita uma avaliação do estado de conservação da edificação. Esse trabalho visa analisar e propor soluções para as manifestações patológicas observadas na unidade de ensino. A metodologia empregada no estudo decorre de análises, provenientes de laudo técnico desenvolvido a partir de vistorias com inspeções visuais, táteis e ensaios de selo de gesso e avaliação das espessuras das fissuras, por meio de régua milimetrada. Nas vistorias foram registradas fotografias, entrevistas com os responsáveis pela manutenção do edifício, gestores e usuários da unidade de ensino. Posteriormente foram propostas soluções e identificado o nível de risco existente. Evidenciou-se que as principais manifestações patológicas foram as fissuras, deslocamento de revestimento, manchas, sobrecarga em elementos de vedação e infiltrações. Estas patologias são observadas nas paredes, pisos e fachadas, sendo recorrentes por toda a edificação. Esses problemas estão associados diretamente à falta de vistorias e manutenção adequada. Conclui-se que a avaliação periódica e um investimento em reparos/manutenção, traria maior segurança e conforto aos usuários, propiciando menores impactos no processo de ensino-aprendizagem.

Palavras-chave: manifestação patológica, ensino-aprendizagem, soluções.

\section{ABSTRACT}

To the develop students' cognitive skills, it is necessary, at least, that building environments do not hinder the teachinglearning process, as in the occurrence of unhealthy places and pathologies. The chosen school has an audience composed of elementary and mostly low-income students. Thus, it implies the need for periodic assessment of the state of conservation of the building, since the last renovation and expansion took place in 2011, since then there is no assessment of the state of conservation of the building. Given this, this work aims to analyze and propose solutions to the pathologies observed in the teaching unit. The methodology used in the study results from analyzes, from a technical report developed from surveys with visual inspections, tactile and plaster seal tests and evaluation of crack thicknesses. In the surveys were recorded photographs, interviews with those responsible for building maintenance, managers and users of the teaching unit. Subsequently, solutions were proposed and the existing risk level identified. It was evidenced that the main pathological manifestations were cracks, coating displacement, stains, overloading of sealing elements and infiltrations. These pathologies are observed in the walls, floors and facades, recurring throughout the building. These problems are directly associated with a lack of surveys and proper maintenance. It is concluded that periodic assessment and an investment in repairs / maintenance would bring greater safety and comfort to users, providing lower impacts on the teaching-learning process.

Keywords: pathological manifestation, teaching-learning, solutions.

\section{INTODUÇÃo}

O termo patologia das edifciações advem de origem grega, pathos, significado relativo à doença, na área da engenharia, o termo é utilizado para enquadrar o estudo da origem, da causa, do mecanismo, da propagação, das consequências e 
terapias das manifestações patológicas identificadas nas cosntruções (SOUZA, 1998). Neste contexto, para Degussa (2003), o termo terapia, refere-se ao processo de reparo ou reforço do elemento, componente, sistema (componente da edificação, ou da edificação como um todo.

Quanto à origem das manifestações patologicas podem ter origem em relação meio ambiente ou microclima ao qual a edificação encontra-se, relacionando-se com agentes químicos, fisícos ou biológicos, (como exemplo, causas naturias como ambientes marinhos, ambientes com alta incidência de sol, chuva), como também, ações acidentais e alotrópicas, como falhas de materiais, erros de projeto, falhas de execução ou decorrnetes de uso e manutenção (HELENE, 1993).

Como decorrência das afirmações anteriores, qualquer tipo de edificação está sujeita à ocorrência de processos patológico e assim, com redução da vida útil de projeto (CREMONINI, 1988), como ambientes escolares, podendo ter origem desde as fases iniciais de planejamento, execução ou posterior à entrega, quando a edificação está na fase de uso, podendo acarretar em problemas estéticos, financeiros, ou em maior grau, risco à integridade e saúde dos usuários da edificação.

Em ambientes de ensino, o risco relacionado à incidência de manifestações patológicas se torna imprecidível, uma vez que, grande parcela dos usuários destas edificações, são crianças, implicando numa necessidade maior de cuidado na manutenção da edificação, para não expô-los aos riscos decorrentes de processos patológicos das edificações, além do impacto financeiro decorrente da ausência de manuteções preventivas e também dos riscos físicos à saúde e ao bemestar dos usuários das edifciações (CARASEK, 1996). Para tal, cabe-se a necessidade de se fazer inspeções nas edificações com a finalidade de promover a sanidade da edifciações, redução de custos com mamutenções corretivas e minimizar os riscos aos usuários. Assim, as Inspeções prediais, de forma geral, podem ser entendidas como avaliações das condições técnicas, de uso e de manutenção das edificações visando orientar a manutenção e obter um panorama da Qualidade Predial Total (OLIVEIRA, 2012).

Assim, este trabalho tem a finalidade de realizar uma inspeção predial como um Check-up da edificação, tendo como escopo um diagnóstico geral sobre o Edifício da Escola Municipal Professora Assunção Gonçalves, identificando as anomalias construtivas e falhas de manutenção que interferem e prejudicam a saúde e habitabilidade, frente ao desempenho dos sistemas construtivos e elementos vistoriados da edificação, com foco inspeções visuais e táteis.

\section{METODOLOGIA}

O presente trabalho foi elaborado com base em inspeções visuais e táteis e registro fotográfico, sendo quadrando como um estudo de caso descritivo das condições gerais da edificação avaliada. O objeto de estudo foi a Escola de Ensino Infantil (EEI) Professora Assunção Gonçalves, localizada na Rua Professora Ivany Feitosa de Oliveira, bairro Tiradentes, na cidade de Juazeiro do Norte, Ceará.A escola foi inaugurada no ano de 1990, tendo como público alvo crianças de até 8 anos de idade.

A Escola situa-se em uma área urbana, em uma via de tráfego médio de veículos (principal rua do bairro), ao lado de um posto de saúde e farmácias além de outras escolas, seu logradouro liga-se à avenida principal da cidade.

Com o intuito de verificar os principais fatores e agentes causadores das manifestações patológicas na edificação, foram realizadas em visitas técnicas, entre os dias 8 a 13 de setembro de 2018 e 17 a 26 de junho de 2019, contando com a presença da direção geral da escola, seus coordenadores e responsáveis pela manutenção da edificação.

Para a classificação das fissuras utilizou-se régua transparente milimetrada e a avaliação da estabilidade e movimentação usou-se o teste com o selo de gesso, no intuito de verificar se as fissuram estavam em movimentando ou estáticas. Vale salientar que o teste foi realizado nos elementos de vedação.

Em fase posterior, foi criado um croqui para uma melhor identificação dos ambientes da edificação, uma vez que não se dispôs das plantas arquitetônicas e dos demais projetos. Com tal informação, pode-se determinar e registrar o local onde foram observadas as manifestações patológicas conforme os ambientes. A distribuição dos ambientes é apresentada na Figura 1. A designação dos ambientes é descrita conforme nomeação abaixo apresentada:
A- Fachada principal (Parede P1)
B- Fachada secundária (Parede P3)
C- Salas da coordenação $1 / 2$ (Parede P22)
D- Salas da coordenação 2/2 (Parede P 17)
E- Salas de aula $1 / 5$ (Parede P10)
F- Salas de aula $2 / 5$ (parede P11)
G- Salas de aula 3/5 (Paredes P12 e P13)
H- Cozinha/refeitório (Paredes P18 e P19)
I- Banheiro coordenação (Paredes P23)
J- Banheiro feminino (Paredes P7 e P9)
K- Banheiro masculino (Paredes P4, P5 e P6)
L- Banheiros construídos pós reforma (Parede P14) 
M- Estacionamento (Parede P14)

N- Muro lateral direito (Parede P21)

O- Muro lateral esquerdo (Parede P21) e esquerdo (Parede P16)

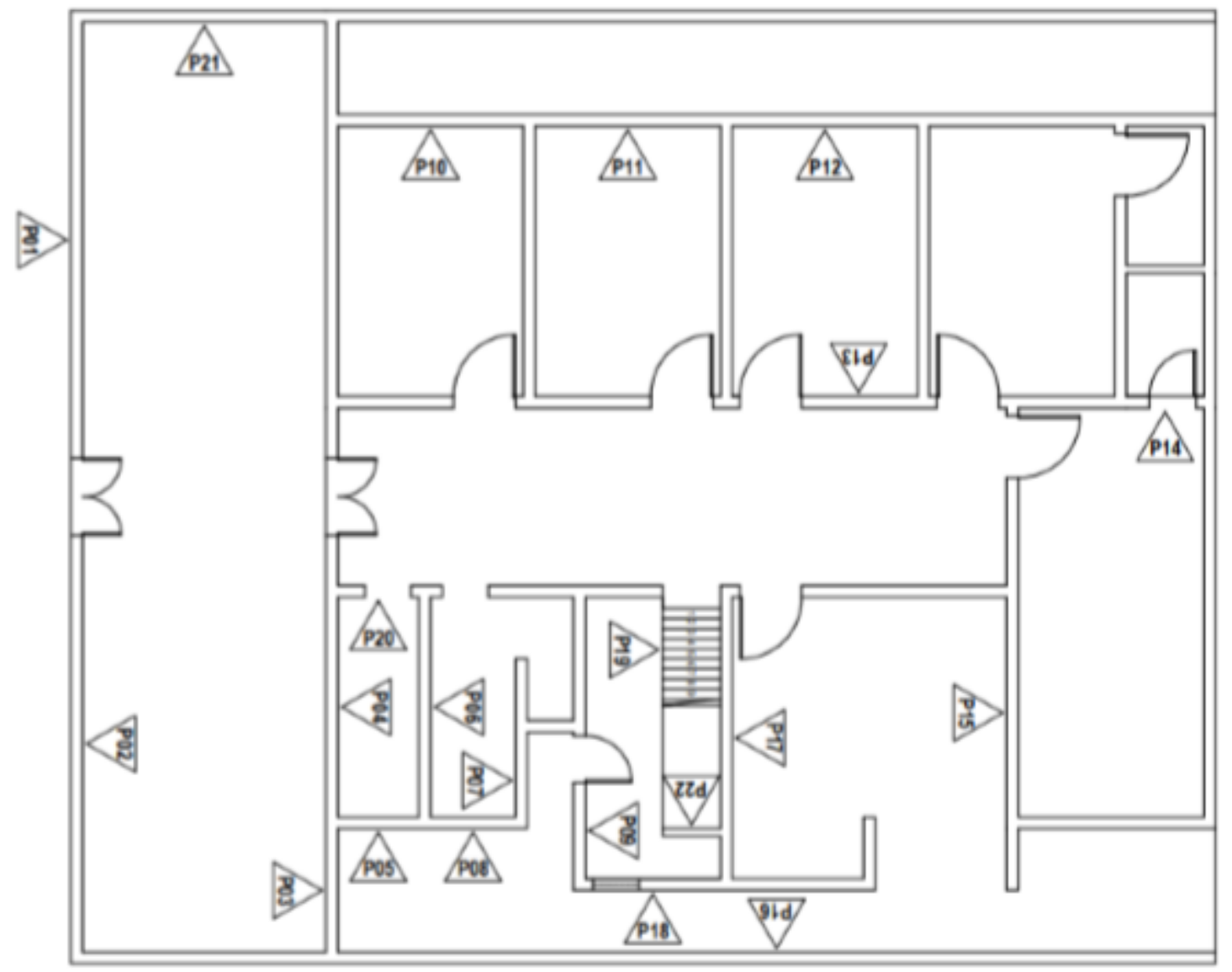

Figura 1 - Croqui indicativo das manifestações patológicas analisadas

Durante a inspeção foi verificado que a edificação analisada conta com uma infraestrutura composta por 1 (um) bloco único, que contém 5 (cinco) salas de aula, 5 (cinco) banheiros, 2 (duas) salas de apoio à coordenação, um (1) refeitório/cozinha, além de uma área livre destinado ao lazer das crianças.

Para cada manifestação patológica apresentada foram elencadas as seguintes informações:

- Registro da patologia por meio de fotos (registro fotográfico);

- Indicação da manifestação patologia;

- Indicação de possíveis causas das manifestações patológicas;

- Indicação de possíveis soluções;

- Classificação quanto ao grau de risco.

A classificação das fissurações segue a determinação em Fissuras, Trinas, Rachaduras, Fenda e Breca, conforme apresentado por Oliveira (2012), sendo apresentada na Tabela 1. 
Tabela 1: Classificação das fissurações

\begin{tabular}{c|c}
\hline Anomalias & Aberturas (mm) \\
\hline Fissura & Até 0,5 \\
\hline Trinca & De 0,5 a 1,5 \\
\hline Rachadura & De 1,5 a 5,0 \\
\hline Fenda & De 5,0 a 10,0 \\
\hline Brecha & Acima de 10,0 \\
\hline
\end{tabular}

Para a classificação quanto aos riscos aos quais os usuários estão expostos, usouu-se como base o trabalho de Carasek (1996), que também auxiliou na orientação de urgências e necessidade de correções das patologias, Os tipos de risco e as especificações são apresentados na Tabela 2.

Tabela 2: Classificação do grau de risco

\begin{tabular}{c|l}
\hline TIPO: & \multicolumn{1}{c}{ ESPECIFICAÇÃO: } \\
\hline CRÍTICO & $\begin{array}{l}\text { Quando pode provocar danos contra a saúde e segurança das pessoas e/ou meio ambiente, perda } \\
\text { excessiva de desempenho causando possíveis paralisações, aumento de custo, comprometimento } \\
\text { sensível de vida útil e desvalorização acentuada. }\end{array}$ \\
\hline MÉDIO & $\begin{array}{l}\text { Pode provocar a perda de funcionalidade sem prejuízo à operação direta de sistemas, perda pontual } \\
\text { de desempenho (possibilidade de recuperação), deterioração precoce e pequena desvalorização. }\end{array}$ \\
\hline MÍNIMO & $\begin{array}{l}\text { Pode causar pequenos prejuízos à estética ou atividade programável e planejada, sem incidência ou } \\
\text { sem a probabilidade de ocorrência dos riscos críticos e regulares, além de baixo ou nenhum } \\
\text { comprometimento do valor imobiliário. }\end{array}$ \\
\hline
\end{tabular}

\section{RESULTADOS}

Em conversa com os responsáveis pela direção, coordenação e manutenção da escola, apontaram que a edificação foi submetida à uma manutenção, por volta do ano 2011, nesta ocasião, ampliou-se o total de salas de aula e banheiros, como também a criação de novos ambientes, na parte superior da edificação, áreas estas destinadas à coordenação e direção do colégio. A seguir são apresentadas as manifestações patologias observadas, conforme a sequência descrita na metodologia.

\section{1 - Fachada Principal (Parede P1)}

Para a fachada principal, observou-se o desplacamento e descoloração da pintura, encontradas na parede da fachada, conforme apresentado nas Figuras 2.

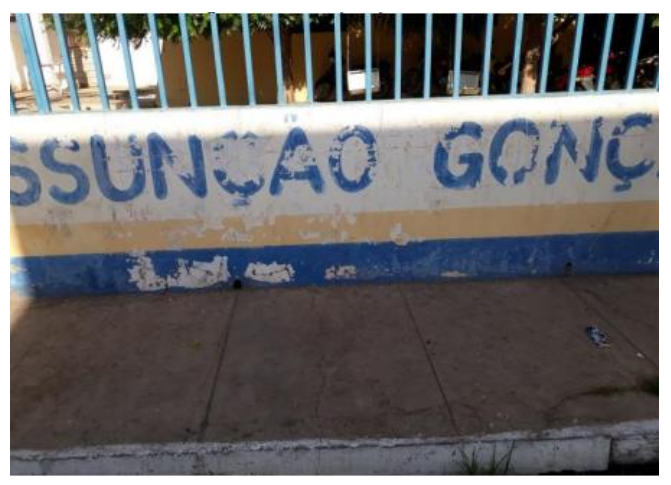

Figura 2 - Fachada principal da escola 
Conforme observado na Figura 2, atribui-se como causa provável para o surgimento do desplacamento e a descoloração, a exposição ao sol (radiação solar), pois esta localiza-se à Oeste, fato agravado em períodos chuvosos. Indicam-se como procedimentos de solução, a retirada da tinta antiga, limpar totalmente o local, com a retirada de camadas de tintas antigas, que reduzem a aderência e a durabilidade do sistema de pinturas. Orienta-se também a manutenção preventiva da pintura da pintura, e o uso de tinta resistente ao calor. Por se tratar de uma patologia com prejuízo estético, classificase como grau mínimo de risco aos usuários.

\section{2 - Fachada secundária- (Parede P3)}

Para a fachada secundária observou-se rachadura com abertura de aproximadamente $5 \mathrm{~mm}$ de espessura na alvenaria e manchas de escoamento de água na fachada, conforme apresentado na Figura 3.

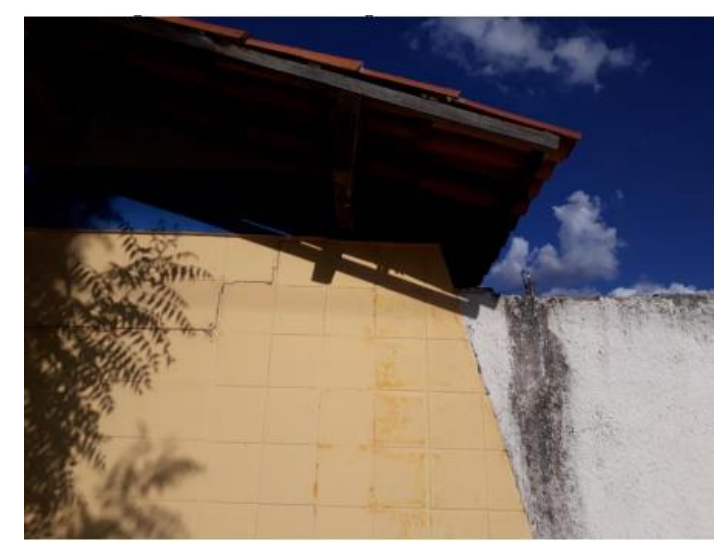

Figura 3 - Trinca relacionada à carga concentrada advinda da estrutura do telhado

Conforme observado na Figura 3, atribui-se como possíveis causas, a sobrecarga advinda da cobertura. Indicam-se como procedimento de solução, a construção de uma viga de amarração superior que apoiaria as linhas da coberta e, assim, distribuiria o carregamento sobre a parede, além da necessidade de reparo na parede em relação a rachadura. Por se tratar de danos não profundos e estáveis, visto com o selo de gesso, indicam-se como grau de risco médio.

\section{3 - Salas da Coordenação (1/2)- (Parede P22)}

Nas salas da Coordenação e diretoria, observam-se trincas, com abertura de aproximadamente $1 \mathrm{~mm}$ de espessura, no piso, conforme observado na Figura 4.

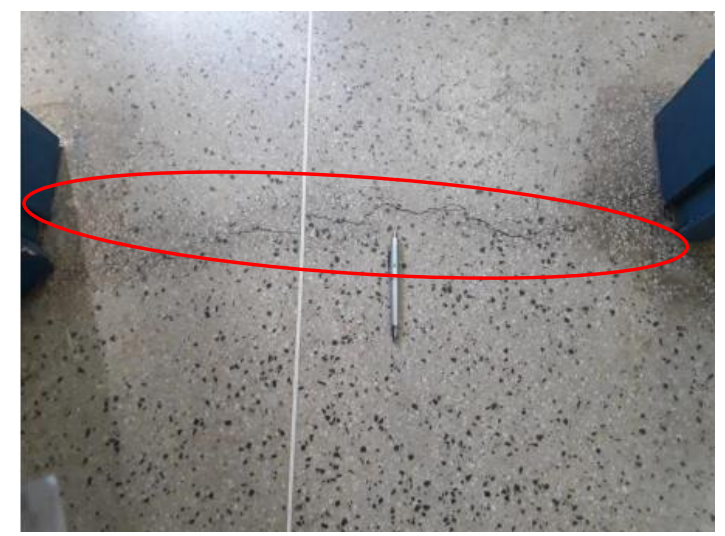

Figura 4 -Entrada da coordenação

Conforme observado na Figura 4, indica-se como causas prováveis acomodação do piso e ausência de frisos. Indicamse como procedimento de solução, uma vez que foi constatado que as trincas não são vivas, por meio de ensaio de selo de gesso, indicando ações corretivas como o fechamento da fissura e, por se tratar de uma manifestação patológica com efeitos estéticos, indica-se um grau mínimo de risco aos usuários. 


\section{4 - Sala da coordenação (2/2 )-(Parede P 17)}

Para a sala da coordenação, verificou-se o aparecimento de fissuras (com aberturas de até $0,5 \mathrm{~mm}$ ) e rachaduras (proximamente $2 \mathrm{~mm}$ de espessura), aberturas pequenas (proximamente $1 \mathrm{~mm}$ de espessura), localizadas na parte superior das aberturas das portas que dão acesso à coordenação (Figura 5).

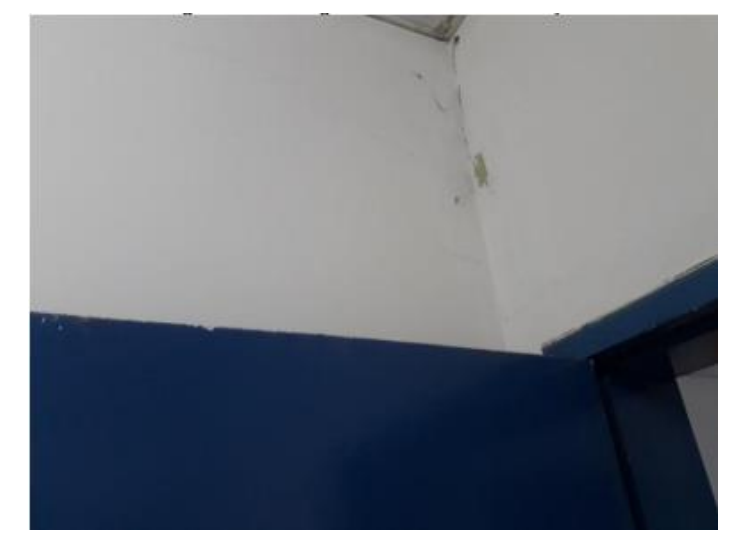

Figura 5 -Patologias em entrada sala de coordenação

Conforme observado na Figura 5, indica-se como causas prováveis a falta de verga na base superior da porta ou possivelmente falta de intertravamento (amarração) entre as alvenarias. Indica-se a verificação da verga, se foi feita da maneira correta e reparar as fissuras observadas. Caso constate-se a falta de amarrações, se faz necessário introduzir elementos de ligação entre as alvenarias, com a abertura de vincos horizontais em ambas as paredes e inserção de hastes e, após a inserção reparar com inserção de argamassa. Por se tratar de uma patologia com efeitos apenas com prejuízo estético, indica-se um grau mínimo de risco aos usuários.

\section{5 - Sala de aula (1/5) - (Parede P10)}

Para a sala de aula (1/5), há um desgaste do piso de concreto, como pode ser observado na Figura 6. Para esta ocorrêcia, que era percebida em diversas salas de aula, indica-se como causas prováveis o desgaste advindo do atrito causado pela circulação dos usuários, atrelado à baixa resistência superficial do piso ao desgaste.

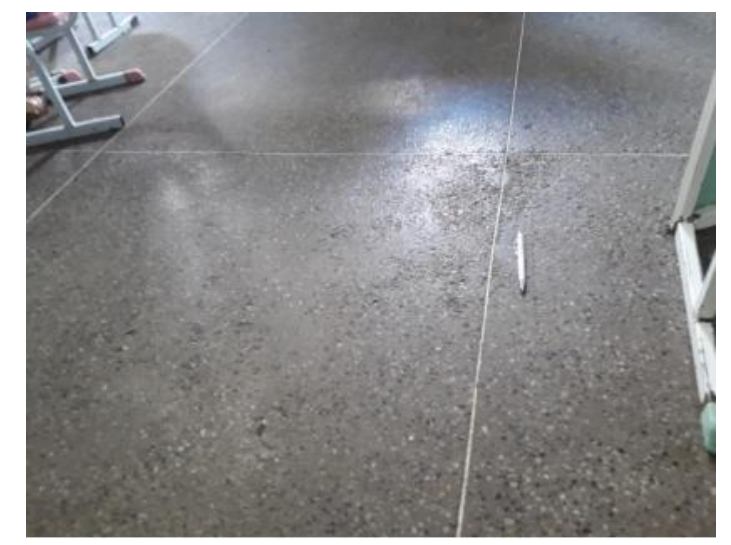

Figura 6 - Piso industrial desgastado

Indicam-se como procedimento de solução, fazer um reparo realizando um polimento da superfície desgastada, como também verificar os estados das carteiras e, se preciso for, colocar proteção de borracha na parte inferior para minimizar o desgaste. Por se tratar de uma patologia com efeitos apenas com prejuízo estético, indica-se um grau mínimo de risco aos usuários.

\section{6 - Sala de aula (2/5) brinquedoteca - (parede P11)}

Para a sala de aula (2/5), usada como brinquedoteca, verificou-se infiltrações e formação de bolores no canto superior. Conforme observado na Figura 7, indica-se como causas prováveis a falta de manutenção/reparo na coberta, além de possíveis falhas nas tubulações de drenagem pluvial. 


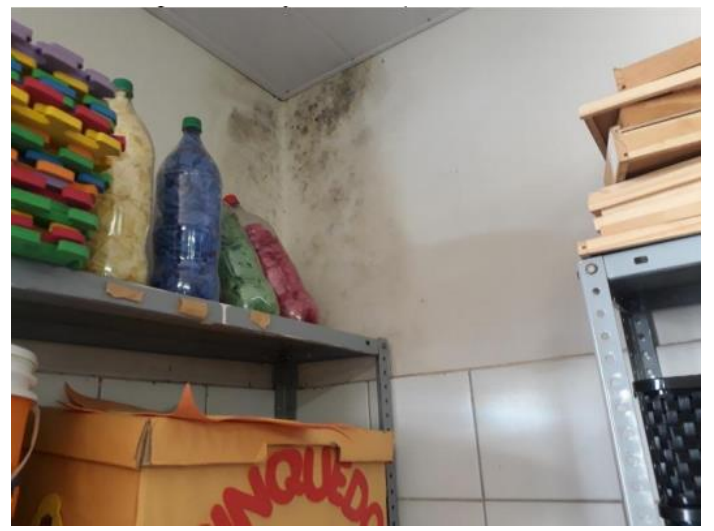

Figura 7 - Infiltração e formação de bolor em sala de aula

.Indicam-se como procedimento de solução, reparo/manutenção na coberta ou da instalação pluvial; trocar possíveis telhas quebradas. Por se tratar de uma patologia que pode causar danos à saúde devido a presença de bolor, exige-se um reparo imediato. Essa manifestação patológica além de prejuízo estético, pode provocar o surgimento de outras patologias associadas à presença de água, destacamento do revestimento argamassado, podendo vir a causar acidentes de maior gravidade, uma vez que se trata de um público infantil. O risco, por sua vez, pode ser classificado como médio, necessitando de reparo urgente.

\section{7 - Sala de aula (3/5)- (Paredes P12 e P13)}

Para sala de aula (3/5), apresenta-se Manifestação de infiltrações, conforme observado nas Figuras 8a e 8b, indica-se como causas prováveis a falta de manutenção/reparo na coberta e nas instalações de drenagem pluvial.
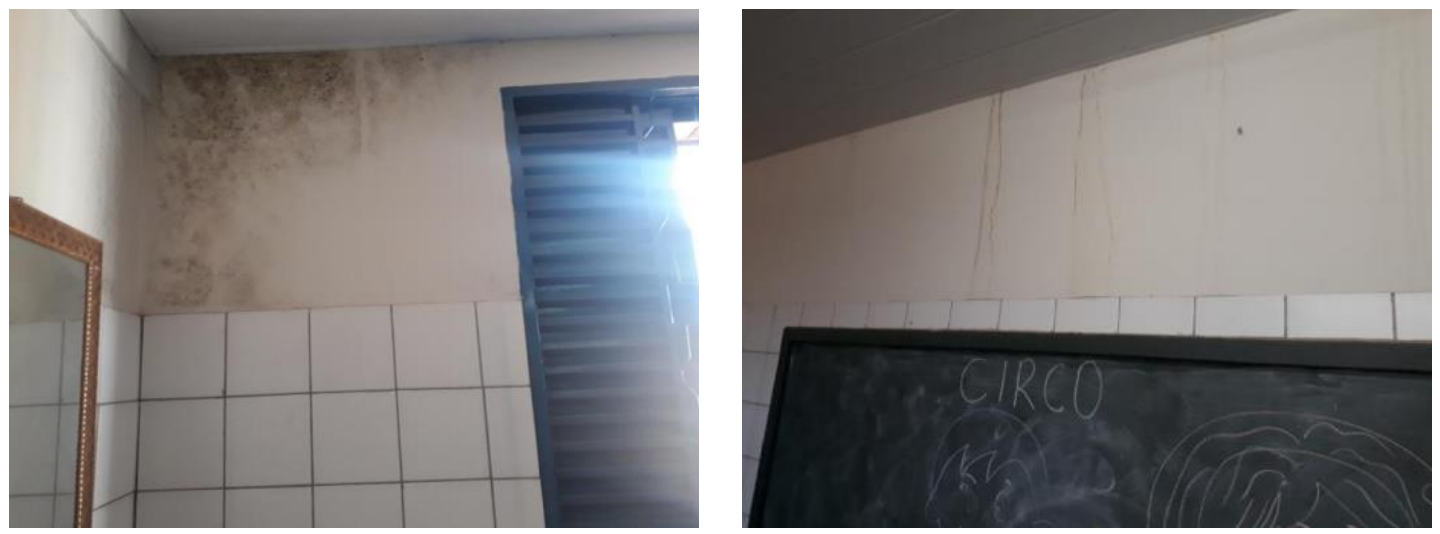

Figura 8 a e Figura 8 b Infiltrações e formação de bolor em sala de aula

Para reduzir ou resolver esta manifestação patológica, sugere-se o reparo/manutenção na coberta ou da instalação hidráulica; com a troca de telhas quebradas, verificar o sistema de suporte do telhado (estrutura de madeira) para possível correção. Além de gerar prejuízos estéticos, essa manifestação patológica pode gerar outras, que por sua vez pode acarretar desplacamento do reboco, além da formação de bolor que pode causar danos à saúde, tornando o local insalubre, necessitando assim, de reparo imediato, logo, indica-se como grau de risco médio ao usuário.

\section{8 - Cozinha/refeitório (Paredes P18 e P19)}

Para a cozinha/refeitório, observam-se rachaduras com aberturas de dimensões variáveis entre $2 \mathrm{~mm}$ e $5 \mathrm{~mm}$, localizadas na ligação da escada com a alvenaria conforme Figura 9. Supõe-se como causas prováveis, sobrecarga distribuída vindo verticalmente da escada associada à ausência de material absorvente do movimento estrutural, reduzindo assim a transferência de esforço para a alvenaria. 


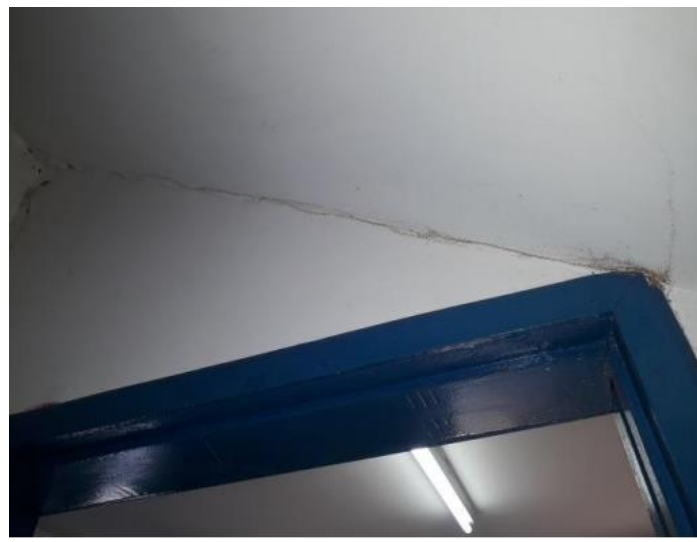

Figura 9 - Escada descarregando sobrecarga em alvenaria

Indicam-se como procedimento de solução, a realizar ensaios de verificação da aderência do reboco e tomar a devida decisão após o prognóstico e inserção de material capaz de absorve as tensões decorrentes do movimento estrutural, tais como argamassa pra encunhamento. Por se tratar de uma patologia que não apresenta movimento, onde foi verificado pelo ensaio com o selo de gesso, pode se concluir que se encontra por momento um risco mínimo aos usuários.

\section{9 - Banheiro da coordenação- (Paredes P23)}

Para o Banheiro da coordenação percebe-se a ocorrência de trincas (aberturas das trincas de aproximadamente $1 \mathrm{~mm}$ de espessura) e de manchas conforme Figura 10. Para as manchas, está diretamente e relacionada com falta de reparo/manutenção no telhado.

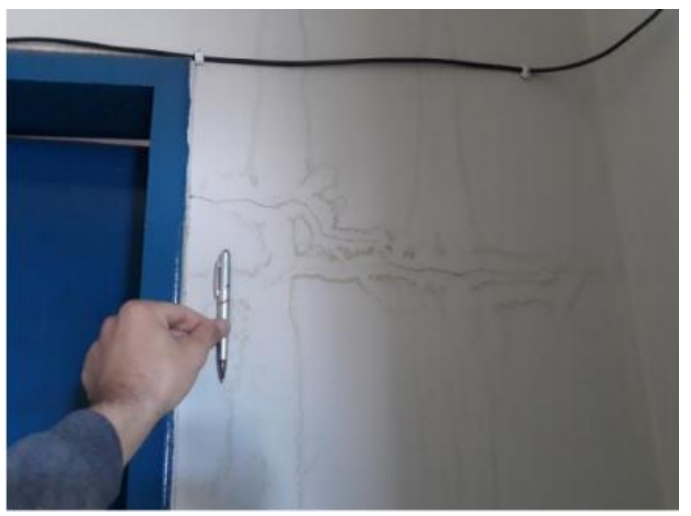

Figura 10 - Manifestação de manchas e trinca

Indicam-se como procedimento de solução, trocar reboco da área afetada e reparar o telhado. Por se tratar de uma patologia com efeitos apenas com prejuízo estético, indica-se um grau mínimo de risco aos usuários.

\subsection{0 - Banheiro feminino (Parede P7 e P9)}

Para o banheiro feminino apresentam-se desplacamento da pintura e trincas, conforme visto nas Figuras $11 \mathrm{a}$ e $11 \mathrm{~b}$. Como medidas corretivas, para as trincas, aponta-se como possível causa a sobrecarga advinda da estrutura de suporte do telhado com apoio direto sobre a alvenaria e o desplacamento da pintura advém da umidade presente na parede, decorrente em parte também da infiltração de água no telhado. 

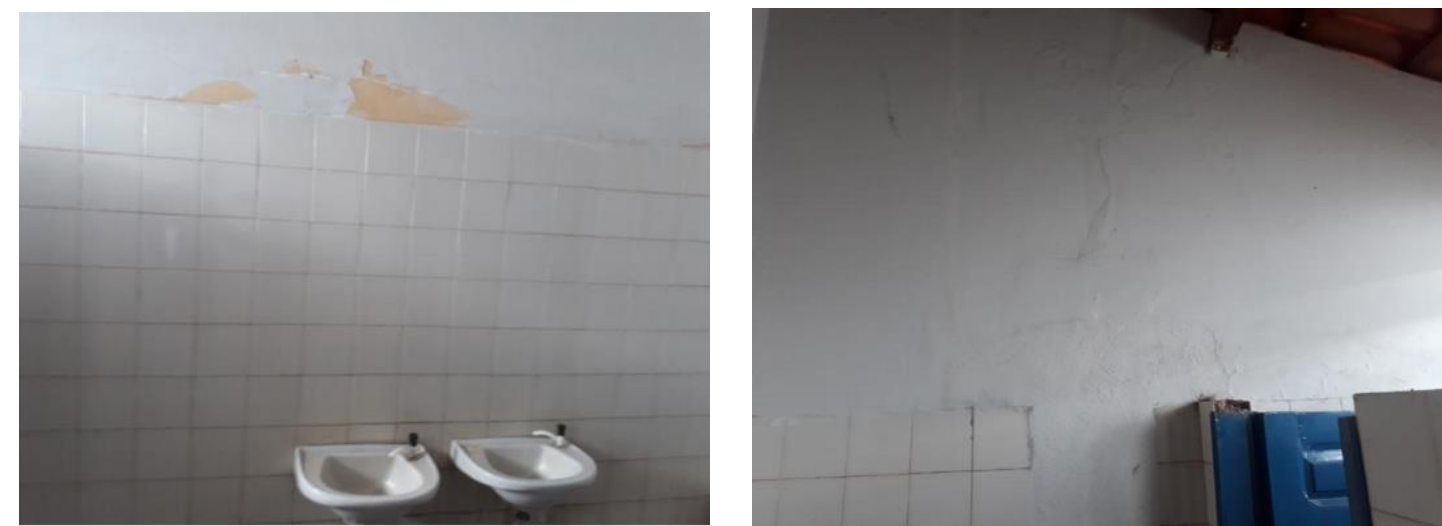

Figura 11 a e Figura 11 b - Manifestação de manchas e trinca em alvenarias no banheiro

Indicam-se como procedimento de solução, reparo na pintura e introdução de base para suporte da linha do telhado com uso de apoios de concreto servindo para distribuir de maneira uniforme o carregamento do telhado sobre a alvenaria. Além desses fatores trazem prejuízos estético afetado pela infiltração na parede, se faz necessário uma intervenção a curto prazo, embora ainda não ofereça riscos à saúde nem a segurança das pessoas, indica-se como grau de risco médio.

\subsection{1 - Banheiro masculino (Paredes P4 ,P5 e P6)}

Para banheiro masculino, apresenta Manifestação de desplacamento do revestimento cerâmico (Figura 12c), acúmulo de água advinda do sistema da tubulação de água (Figura 12b), além de rachadura com abertura média de aproximadamente $5 \mathrm{~mm}$ de espessura (Figura 12a).

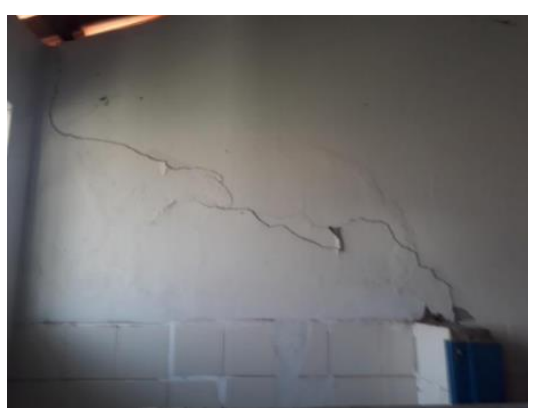

Figura 12 a - Trincas nas paredes do banheiro

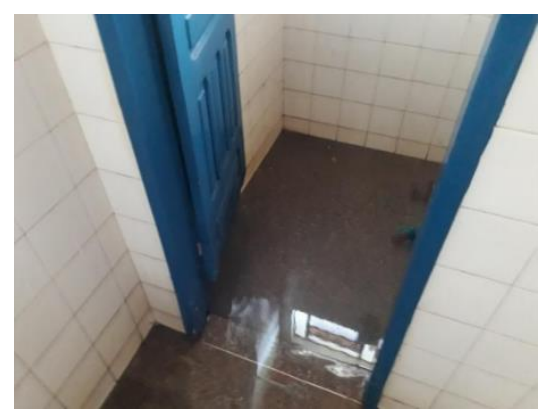

Figura 12 b - Infiltração no piso do banheiro

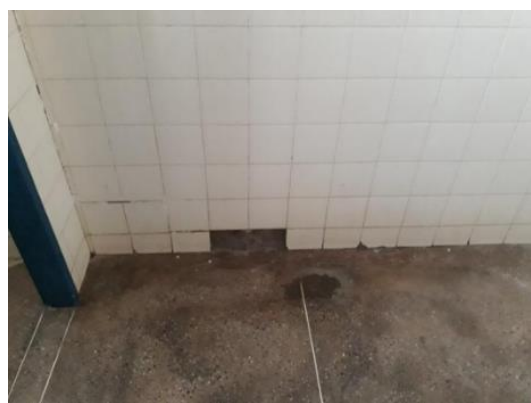

Figura $12 \mathrm{c}$ - Desplacamento cerâmico nas alvenarias do banheiro

Conforme observado na Figura 12 b, indica-se como causas prováveis desgaste, como também a falha dos elementos de vedação das tubulações hidráulicas, uma vez que se tratava de água da rede de abastecimento, relacionada com a falta manutenção que pode afetar a pintura e causar o desplacamento do revestimento cerâmico (Figura 12 b). Observa-se também na Figura $12 \mathrm{c}$, para o mesmo ambiente, rachaduras possivelmente relacionadas à sobrecarga advinda de esforço concentrado da linha do telhado. Indicam-se como procedimento de solução, reparo/manutenção da instalação hidráulica, nivelamento do piso e renovar a instalação hidráulica, renovar o reboco e introduzir uma base para suporte da linha do telhado com uso de apoios de concreto servindo de assento para a linha do telhado. Por se tratar de junção de vários riscos e danos à saúde e a segurança das crianças, necessita-se de reparo imediato, sendo indicado um grau de risco alto aos usuários. 


\subsection{2 - Banheiros construídos pós reforma (P14)}

Para os banheiros construídos pós reforma, apresenta-se o registro do chuveiro defeituoso, conforme representado na Figura 13.

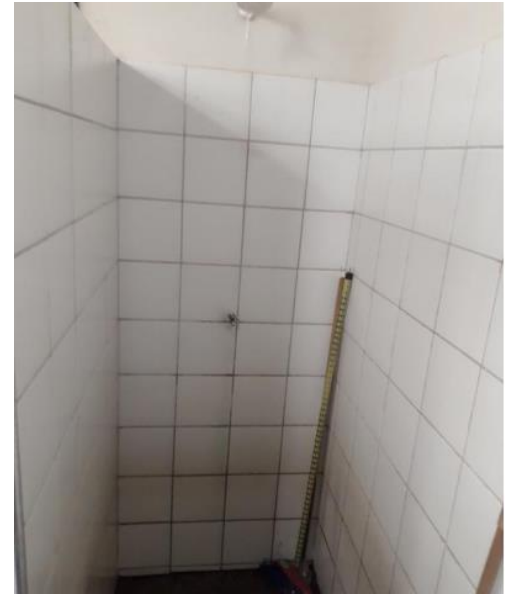

Figura 13 - Vazamento na válvula do registro

Conforme observado na Figura 13, indica-se como causas prováveis a ausência de manutenção adequada. Indicam-se como procedimento de solução, trocar o a peça danificada. Embora haja perda da funcionalidade e mesmo havendo desperdício de água podendo causar uma serie de infiltrações que podem comprometer todo banheiro, a patologia encontre-se em estado inicial e a intervenção pode ser realizada à curto prazo sem grandes prejuízos, porém, indica-se um grau de risco médio aos usuários.

\subsection{3 - Estacionamento (P2)}

Para o estacionamento, apresenta fendas (aberturas entre $5 \mathrm{~mm}$ a $10 \mathrm{~mm}$ ) e brechas com abertura média de $2 \mathrm{~cm}$ de espessura, observadas nas Figura 14a e 14 b.
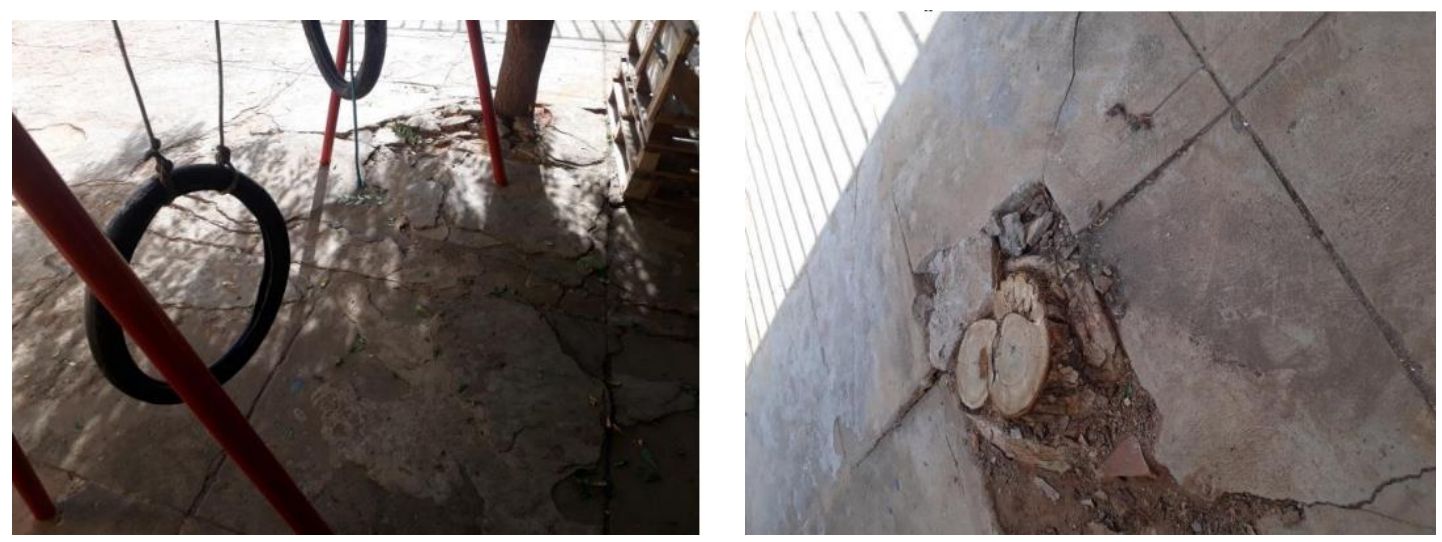

Figura 14 a e Figura 14 b - Fissuras no Piso do estacionamento interno da escola

As causas prováveis podem decorrer da expansão do solo devido à presença de raízes superficiais das árvores. Como procedimento de solução sugere-se a retirada das raízes e construir outro piso. Para este ambiente, indica-se um grau de risco alto, uma vez que expõe à segurança das pessoas, sendo estas passivas de queda ou tropeços, sendo recomendo a intervenção em curto prazo.

\subsection{4 - Muro lateral direito (Parede P21) e esquerdo (Parede P16)}

Para o muro lateral direito, verifica-se desplacamento da pintura e mancha de umidade. Conforme observado nas Figuras 15a e 15b, para ambos os ambientes, apontam-se como causas prováveis a Infiltração causada por águas da chuva incidindo diretamente no muro e por falta de impermeabilização nas fundações. 


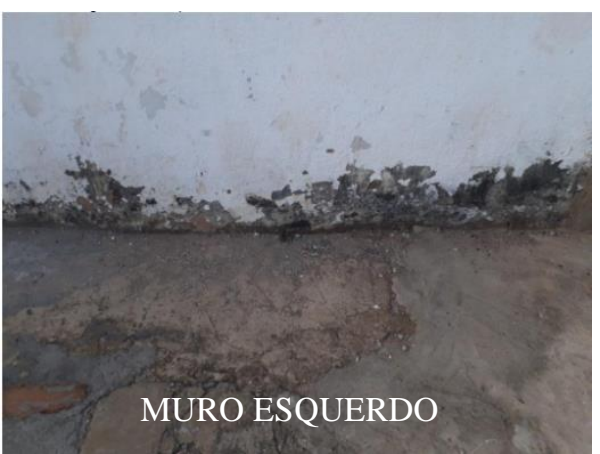

Figura 15 a - Muro lateral esquerdo

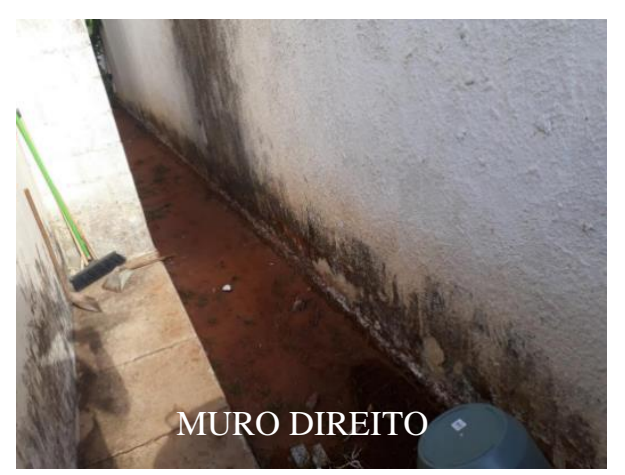

Figura 15 a - Muro lateral direito

Indicam-se como procedimento de solução, remover o reboco das áreas mais afetadas (devido à falta de impermeabilização das fundações) e aplicar impermeabilizante. Reparo/manutenção da pintura, fazer a retirada com espátula e lixa de toda a tintura envelhecida, posteriormente aplica-se um selador e uma camada de massa corrida, por último aplica-se a tinta renovando assim a estética. Indica-se grau de risco crítico ao usuário, pois além de causar prejuízo estético, também pode ser maléfico a saúde das pessoas, pois, torna o local insalubre, caso não haja um reparo, o problema pode se agravar a longo prazo provocando o desplacamento do revestimento argamassado.

\section{CONCLUSÕES}

Com a realização do trabalho foi possível diagnosticar que a estrutura da Escola de Ensino Infantil Professora Assunção Gonçalves, apresenta manifestações patológicas como fissuração, sendo as rachaduras e trincas mais frequentes. Porém, de acordo com os testes de gesso, nenhuma destas manifestações patológicas apresentam indícios de movimentação sendo consideradas estáticas. Essas anomalias por sua vez, estão ligadas, possivelmente, à sobrecarga do telhado que se apoio diretamentoe sobre as alvenarias ou má execução da obra ou reforma e ausência de manutenção preventiva.

No que diz respeito às manchas e infiltrações, foi constatado que ocorrem devido à falta de manutenção no telhado e vazamentos das instalações hidráulicas.

Para as instalações hidrossanitárias, sistema de pinturas e piso, as manifestações patológias podem ser reduzidas com manutenções períodoicas associadas à inspeções visuais e com pequenos reparos, evitando assim que as mesmas evoluam de grau mínimo para grau alto e de maior custo de correção.

Por fim, o grau de risco pode ser classificado, em sua maioria graus médios, visto que na análise foi levado em consideração que a escola é de ensino fundamental 1, onde seus alunos são crianças e elas são mais suscetíveis à doenças respiratórias e as más condições de segurança oferecidas pela estrutura desta escola e mínimos, pois, muitos dos problemas apresentam apenas prejuízo estético, sem maiores problemas aos processos de ensino-aprendizagem, uma vez que não há a necessidade de interdição ou interrupção das atividades na escola.

\section{REFERÊNCIAS}

CARASEK, H. Aderência de argamassas à base de cimento Portland a substratos porosos: avaliação dos fatores intervenientes e contribuição ao estudo do mecanismo da ligação. São Paulo, 1996. Tese de Doutoramento - Escola Politécnica da USP.

CREMONINI, Ruy Alberto. Incidência de manifestações patológicas em unidades escolares da região de Porto Alegre:Recomendações para projeto, execução e manutenção. Porto Alegre, 1988

DEGUSSA. Manual de Reparo, Proteção e Reforço de Estruturas de Concreto. 2003. Ed. Red. Rehabilitar. São Paulo, 2003.

HELENE, Paulo. Manutenção para Reparo, Reforço e Proteção de Estruturas de Concreto. Pini, $2^{a}$ ed. São Paulo, 1992.

OLIVEIRA, Alexandre Magno. Fissuras e rachaduras causadas por recalque diferencial de fundações. $2012.96 \mathrm{f}$. Monografia (Espacialização em Gestão em Avaliações e Perícias) - Universidade Federal de Minas Gerais, Minas Gerais, 2012.

SOUZA, Vicente Custódio Moreira de; RIPPER, Thomaz. PATOLOGIA, RECUPERAÇÃO E REFORÇO DE ESTRUTURAS DE CONCRETO. $2^{\mathrm{a}}$ ed, São Paulo: Pini, 2009. 